\title{
Novel approach for phacoemulsification during combined phacovitrectomy
}

\author{
This article was published in the following Dove Press journal: \\ Clinical Ophthalmology \\ 15 December 2015 \\ Number of times this article has been viewed
}

\author{
Wael Ahmed Ewais \\ Ashraf Abdel Maqsoud \\ Nossair \\ Lamia Samy Ali \\ Department of Ophthalmology, \\ Faculty of Medicine, Cairo University, \\ Cairo, Egypt
}

Purpose: To evaluate the safety and efficacy of surgeon's superior sitting position during temporal clear corneal incision (TCCI) phacoemulsification, with a $90^{\circ}$ working angle, during combined phacovitrectomy.

Methods: Prospective interventional case series were performed on 65 eyes of 63 patients. TCCI phacoemulsification was done in all cases (whether right or left eyes), while the surgeon was sitting superiorly to the operating table.

Outcome measures included: Shift in sitting position, keratometric astigmatism, surgically induced astigmatism, posterior capsule integrity, and intraocular lens centration.

Results: Phacoemulsification was performed completely in all cases (100\%). Shift in position to temporal sitting position happened in two cases $(3 \%)$. The keratometric astigmatism showed mean changes of $1.09 \mathrm{D}(0.25-3.75 \mathrm{D})$ to $0.84 \mathrm{D}(0.00-3.25 \mathrm{D})$ at 1 month, which remained stable at 6 months; $0.84 \mathrm{D}(0.16-3.21 \mathrm{D})$. The surgically induced astigmatism was $0.25 \mathrm{DC}$ $(-0.50$ to $1.0 \mathrm{DC})$ at 1 month, which stayed stable at 6 months; $0.25 \mathrm{D}(-0.63 \mathrm{D}$ to $0.98 \mathrm{D})$. Posterior capsular rupture occurred in one case (the second case) $(1.5 \%)$. The intraocular lens was centered in all cases (100\%).

Conclusion: Superior sitting TCCI phacoemulsification, with a wide working angle, during combined phacovitrectomy proved safe and easy, without the burden of changing and disrupting the operative setting. The anatomical and optical outcomes were acceptable.

Keywords: clear corneal incisions, temporal nasal horizontal superior, surgically induced astigmatism, keratometric astigmatism, superior sitting position, working angle

\section{Introduction}

Combined cataract and vitreoretinal surgery (phacovitrectomy) has gained popularity in the recent years. The combined surgery offers advantages including: adequate visualization of the posterior segment, adequate access to the vitreous base, more rapid visual recovery, and avoiding the need for cataract surgery in the vitrectomized eye. Cataract surgery in a vitrectomized eye is risky because of instability of the zonules and posterior capsule, absence of vitreous support, and adherent posterior subcapsular plaques. ${ }^{1-5}$

The most common approach for phacoemulsification is temporal, where the surgeon sits at a temporal position to the surgical table, and performs the procedure through a temporal clear corneal incision (TCCI). The working angle is usually approximately $45^{\circ}$. The advantages of temporal approach include: it induces the least surgically induced astigmatism (SIA); it provides adequate visualization of the posterior segment because the temporal incision is further from the visual axis than the superior incision; it provides better accessibility, especially in deep set eyes or prominent orbital rims; and it offers an excellent red reflex. ${ }^{5-9}$

The major drawback for the temporal approach during combined phacovitrectomy is that the surgeon and assistants need to arrange the situation with the operating table and
Correspondence. Wael Ahmed Ewais Department of Ophthalmology, Faculty of Medicine, Cairo University, 24 Shehab Street, Mohandessin, PO Box I I4II

Cairo, Egypt

Tel +2023762 339

Email waelewais74@gmail.com 
move their operating position after finishing the phacoemulsification and before starting the pars plana vitrectomy. This entails shifting the position of various machines and tables in the operating room, which is close to the patient's bed. ${ }^{6}$

This study was designed so that the surgeon attains a superior sitting position, but performs the phacoemulsification through a TCCI. The working angle is approximately $90^{\circ}$ (between the surgeons viewing axis and the phaco probe axis). This achieves the advantages of temporal phacoemulsification without changing position during the combined phacovitrectomy. This approach avoids shifting of surgical machines and tables in the operating room. This means that there is much less interruption, time loss, and less entrance by technicians and nursing staff. This reduces the operative time, and reduces the risk of postoperative endophthalmitis.

\section{Patients and methods}

This prospective consecutive interventional case series included 65 eyes of 63 patients. Superior sitting temporal incision phacoemulsification was performed during the combined phacovitrectomy in all the cases. The surgeries were performed by a single surgeon (WAE) from December 2013 to August 2014. Approval from the Research Ethics Committee of the Faculty of Medicine, Cairo University was obtained. Written informed consents were obtained from all the patients.

Inclusion criteria included: candidates for phacovitrectomy with clear cornea. Exclusion criteria included: lens subluxation, trauma cases, corneal opacity, keratoconus or keratectasia, and irregular astigmatism.

Preoperative evaluation was done for keratometric astigmatism (KA) as part of the optical biometry (IOL Master).

\section{Surgical procedure}

The cases were performed under local peribulbar anesthesia in 55 cases $(84.6 \%)$, and general anesthesia in ten cases $(15.4 \%)$.

Surgeries were performed by one surgeon (WAE). The surgeon sat at the head of the table at 12 o'clock position (superior sitting position).

Two side port $19 \mathrm{G}$ micro vitreoretinal blade incisions were done at 6 and 12 o'clock positions, respectively, followed by the main stab keratome incision, which was done clear corneal, uniplanar, with a $2.4 \mathrm{~mm}$ width. The keratome incision was done along the horizontal meridian temporally at 3 o'clock in left eyes and at 9 o'clock in right eyes.

Conventional coaxial phacoemulsification was done in all cases, with the horizontal orientation of the phaco probe, $90^{\circ}$ working angle.

A foldable intraocular lens (IOL) was implanted in the capsular bag. It was a $6 \mathrm{~mm}$ hydrophobic acrylic IOL (Alcon
Acrysof SA60, Alcon Laboratories Inc., Fort Worth, TX, USA). The IOL was implanted using an injector system (Monarch, Alcon Laboratories Inc.).

The stab incision was secured with a single radial 10/0 nylon suture, which was removed at the end of the surgery.

After all phacoemulsification was done, 23G trocars (Alcon 23G, Alcon Laboratories Inc.) were inserted in an oblique single step fashion $3.0 \mathrm{~mm}$ from the limbus, and vitrectomy was then performed. The tamponading agent used at the end of surgery was either air, sulfur hexafluoride 6 (SF6) gas, or silicone oil.

The outcome measures included shift of position to temporal sitting during the procedure, posterior capsule integrity during the procedure, IOL centration, KA, and SIA. IOL centration was defined as equally distanced IOL optic edges from the edge of the capsulorhexis.

The postoperative evaluation was performed 1 day after the procedure for IOL centration, and keratometry was done 1, 3, and 6 months, after the procedure for KA, IOL Master optical biometry was used for KA measurement. SIA was calculated, from KA, by the vector analysis formula using the Holladay-Cravy-Koch formula. ${ }^{10}$

\section{Results}

The study was performed on 65 eyes of 63 patients, including 28 male patients (43\%) and 37 female patients (57\%).

The mean age was 50 years (standard deviation [SD]: 12, 19-74 years). Sixty-five percent of the patients were $\geq 50$ years old. Age distribution is illustrated in Figure 1.

Systemic disease: eight cases were diabetic (12.3\%), 24 cases had both diabetes mellitus and systemic hypertension (36.9\%), and six cases were hypertensive only (9.2\%).

The ocular indications for combined phacovitrectomy included: proliferative diabetic retinopathy in 15 cases $(23.1 \%)$, tractional diabetic macular edema in 14 cases $(21.5 \%)$, simple rhegmatogenous retinal detachment in

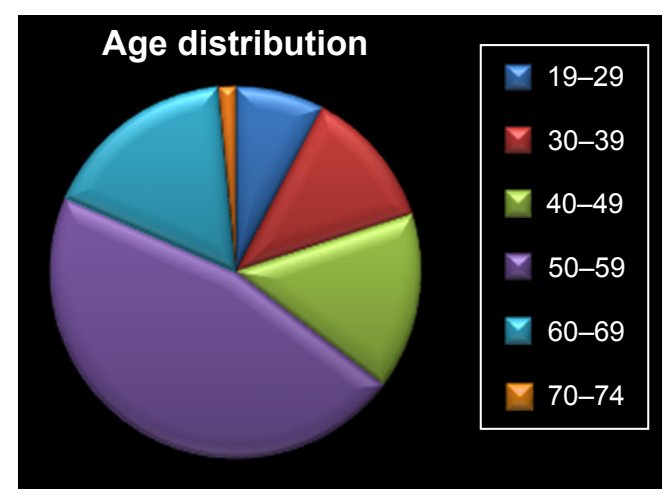

Figure I Age distribution (in years) of the cases. 


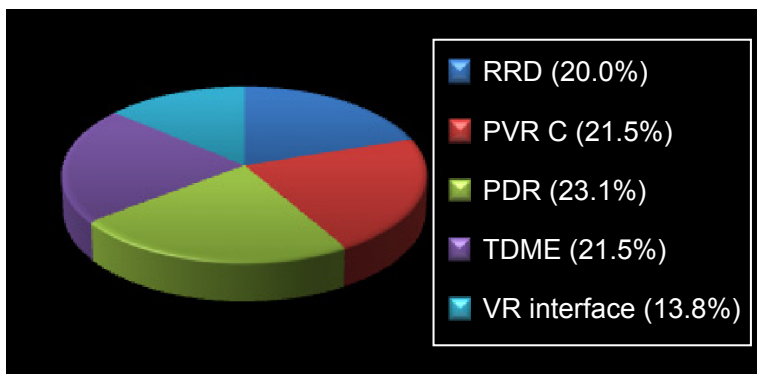

Figure 2 Indications for phacovitrectomy.

Abbreviations: RRD, simple rhegmatogenous retinal detachment (with PVR 0, A, B); PVR, proliferative vitreoretinopathy; PVR C, proliferative vitreoretinopathy grade C; PDR, proliferative diabetic retinopathy; TDME, tractional diabetic macular edema; VR interface, vitreoretinal interface.

13 cases (20\%), proliferative vitreoretinopathy in 14 cases $(21.5 \%)$, and vitreoretinal interface disorders in nine cases (13.8\%). They are displayed in Figure 2.

The crystalline lens was clear in 19 cases $(29.2 \%)$, with a mature cataract in six cases $(9.2 \%)$, nuclear I cataract in 12 cases (18.5\%), and nuclear II and III in 28 cases (43.1\%). Figure 3 illustrates lens status.

Baseline criteria are demonstrated in Table 1.

Intraoperative shift in position from superior sitting to temporal sitting was needed in two cases (3.1\%); they were the second and the third cases in the study.

Posterior capsule remained intact in 64 cases (98.5\%). It was ruptured in only one case (1.5\%), and this was the second case in the study. This case had a mature nuclear cataract.

The IOL was centered in the capsular bag at day 1 in all cases $(100 \%)$.

\section{KA}

The mean preoperative KA was $1.09 \mathrm{DC}$, with an SD of 0.65 , and a range $0.25-3.75 \mathrm{DC}$.

There was a statistically significant change in the mean postoperative KA, 1 month after the procedure, to $0.84 \pm 0.58$

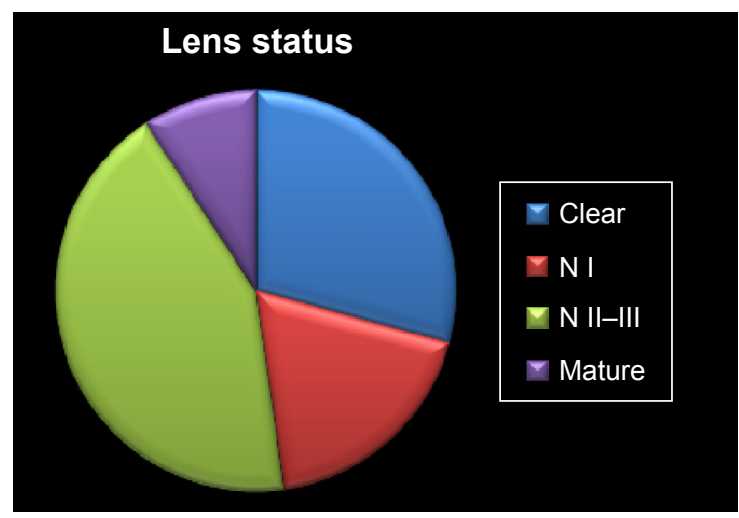

Figure 3 Baseline lens status.

Notes: $\mathrm{N} \mathrm{I}=$ nuclear cataract grade I (mild density, yellowish). $\mathrm{N} \mathrm{II-III=} \mathrm{nuclear}$ cataract grades II and III (moderate density, greenish brown).
Table I Baseline demographic and clinical data

\begin{tabular}{lll}
\hline Baseline criteria & Results & Range (\%) \\
\hline Male/female & $28 / 37$ & $43 / 57$ \\
Age (years) & 50 & $19-74$ \\
DM & 8 & 12.3 \\
DM and HTN & 24 & 36.9 \\
HTN & 6 & 9.2 \\
PDR & 15 & 23.10 \\
TDME & 14 & 21.50 \\
RRD & 13 & 20 \\
PVR & 14 & 21.50 \\
VR interface & 9 & 13.80 \\
\hline
\end{tabular}

Abbreviations: RRD, simple rhegmatogenous retinal detachment (with PVR 0, A, B); PVR, proliferative vitreoretinopathy; PVR C, proliferative vitreoretinopathy grade C; PDR, proliferative diabetic retinopathy; TDME, tractional diabetic macular edema; VR interface, vitreoretinal interface; DM, diabetes mellitus; HTN, hypertension.

DC, with a range $0.00-3.25$ DC $(P<0.05)$. KA remained stable over 3 and 6 months; respectively, $0.84 \pm 0.58 \mathrm{DC}$ and $0.84 \pm 0.57$ DC $(P>0.05)$.

Change in KA is illustrated in Figure 4.

Keratometric data were reviewed to identify the pattern of astigmatism; whether with the rule (WTR), or against the rule (ATR). Most of the cases had preoperative ATR astigmatism, 61 eyes (93.8\%). WTR astigmatism existed in only four eyes $(6.2 \%)$.

WTR astigmatism worsened significantly at 1 month from a baseline mean $1.06 \pm 0.31 \mathrm{D}$ to a mean $1.44 \pm 0.24 \mathrm{D}$ $(P<0.05)$. There was an insignificant change at 3 months; $1.59 \pm 0.21 \mathrm{D}$, and at 6 months $1.55 \pm 0.16 \mathrm{D}(P>0.05)$. Change in WTR astigmatism is illustrated in Figure 5.

ATR astigmatism improved significantly from a mean baseline $1.09 \pm 0.67 \mathrm{D}$ to $0.80 \pm 0.58 \mathrm{D}$ at 1 month $(P<0.01)$. However, there was an insignificant change at 3 and 6 months; consecutively, $0.79 \pm 0.56 \mathrm{D}(P>0.05)$ and $0.79 \pm 0.56 \mathrm{D}$ $(P>0.05)$. Changes in ATR astigmatism are illustrated in Figure 6.

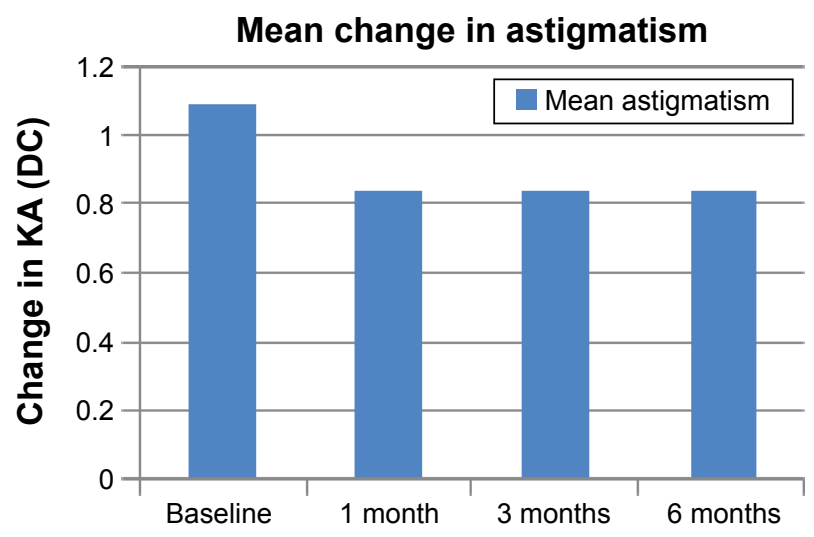

Figure 4 Change in KA.

Abbreviation: KA, keratometric astigmatism. 


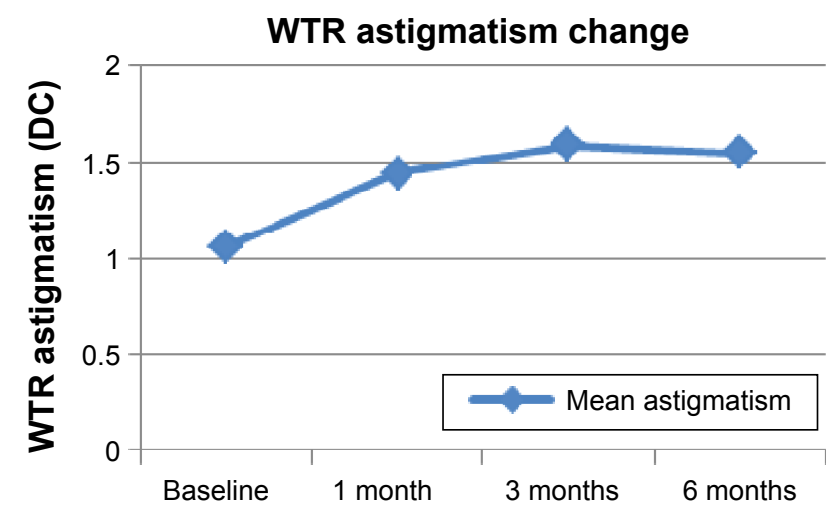

Figure 5 Change in WTR astigmatism.

Abbreviation: WTR, with the rule.

The SIA was $0.25 \pm 0.4 \mathrm{DC}$ at 1 month. SIA remained stable; $0.25 \pm 0.4 \mathrm{D}$ at 3 months and $0.25 \pm 0.39 \mathrm{D}$ at 6 months.

In the four WTR astigmatism cases, there was an initial statistically insignificant increase in SIA from a mean $0.38 \pm 0.14 \mathrm{D}$ at 1 month to $0.53 \pm 0.12 \mathrm{D}$ at 3 months $(P>0.05)$, followed by a statistically insignificant reduction to a mean $0.48 \pm 0.16 \mathrm{D}$ at 6 months $(P>0.05)$. SIA changes are illustrated in Figure 7.

In the 61 cases of ATR astigmatism, SIA remained stable over the 6 months, as shown in Table 2 and Figure 8.

There was almost no relation between the age of patients and the baseline KA, $\mathrm{r}(63)=0.22, P>0.05$, in addition to the SIA, r $(63)=0.17, P>0.05$. However, there was an insignificant strong positive relation between age and SIA in ATR astigmatism cases, $\mathrm{r}(63)=0.70, P>0.05$. There was no relation between sex of patients and KA (r [63] $=0.06, P>0.05)$, and SIA (r [63] $=0.09, P>0.05)$.

There was a significant moderate relation between diabetes mellitus (DM) and baseline KA, r (63) $=0.31$, $P<0.01$. However, there was no relation between systemic hypertension and baseline KA (r [63]=0.05,

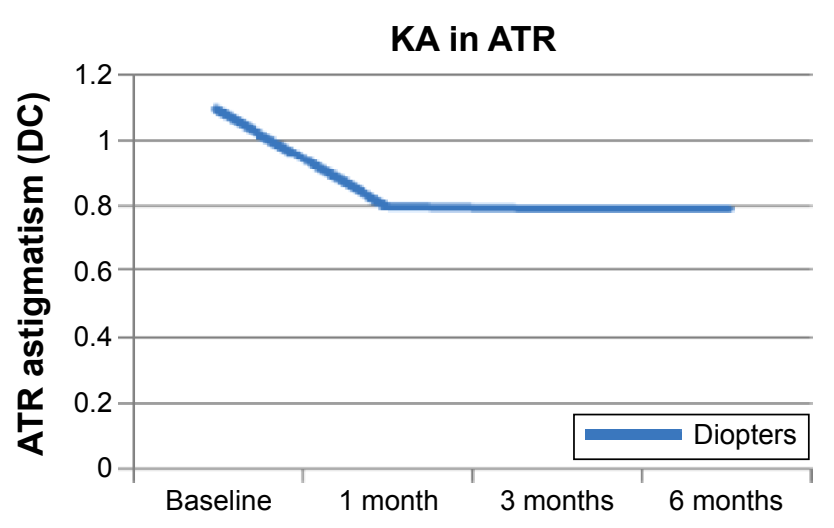

Figure 6 Change in ATR astigmatism.

Abbreviations: KA, keratometric astigmatism; ATR, against the rule.

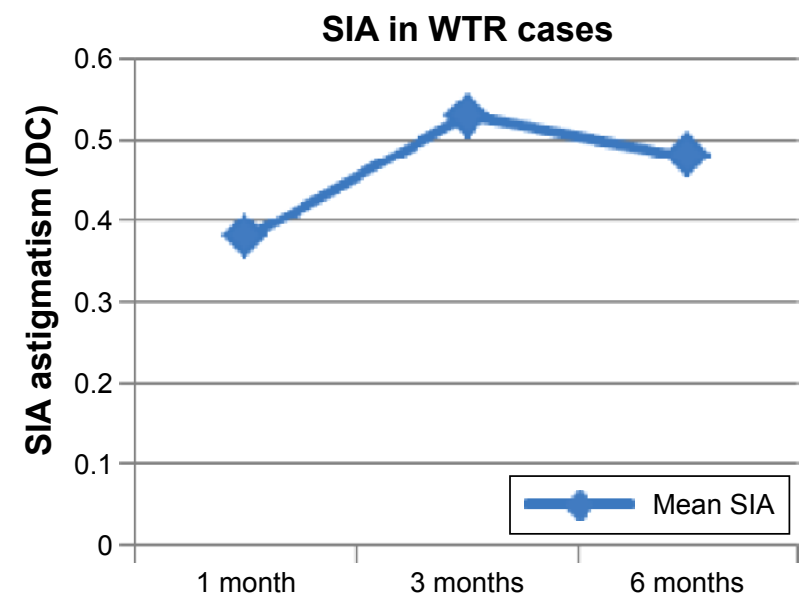

Figure 7 SIA changes in WTR astigmatism cases.

Abbreviations: SIA, surgically induced astigmatism; WTR, with the rule.

$P>0.05)$. There was no correlation between the underlying indications for vitrectomy and the baseline KA (r [63] $=0.24, P<0.05)$, and SIA (r [63] $=0.05, P>0.05)$. There was no relation between the lens status and baseline KA (r $[63]=0.09, P>0.05$ ), and the SIA (r $[63]=0.09, P>0.05$ ).

Tamponading agents were used in the cases as follows: Air in 22 eyes (33.8\%), SF6 gas in 19 eyes (29.2\%), and silicone oil in 24 eyes (36.9\%). Figure 9 illustrates tamponading agents in the study.

The study proves that there is a weak relationship between the used tamponade and baseline KA, postoperative KA in the cases, preoperative: $\mathrm{r}(63)=0.28, P<0.05$, and postoperative $\mathrm{r}(63)=0.28, P<0.05$. Silicone oil cases had the largest mean preoperative and postoperative KA; $1.30 \mathrm{D}$ and $1.06 \mathrm{D}$, consecutively. However, there was no relationship between the tamponade and the SIA, $\mathrm{r}(63)=0.05, P>0.05$, thus confirming the null hypothesis. Preoperative and postoperative mean KA, for cases according to the used tamponade, are listed in Table 3 and Figure 10.

\section{Discussion}

TCCIs elicit less astigmatism than superior clear corneal incisions. Our study achieved 0.25 DC SIA, compared to $0.87 \mathrm{DC}$ induced by superior clear corneal incisions in a study done by Lee et al. ${ }^{1}$ Even though the SIA gradually decreased

Table 2 SIA changes in ATR astigmatism cases

\begin{tabular}{lll}
\hline Follow up & SIA (mean \pm SD) & $P$-value \\
\hline I month & $0.30 \pm 0.37$ & \\
3 months & $0.30 \pm 0.36$ & $>0.05$ \\
6 months & $0.30 \pm 0.35$ & $>0.05$ \\
\hline
\end{tabular}

Abbreviations: SIA, surgically induced astigmatism; ATR, against the rule; SD, standard deviation. 


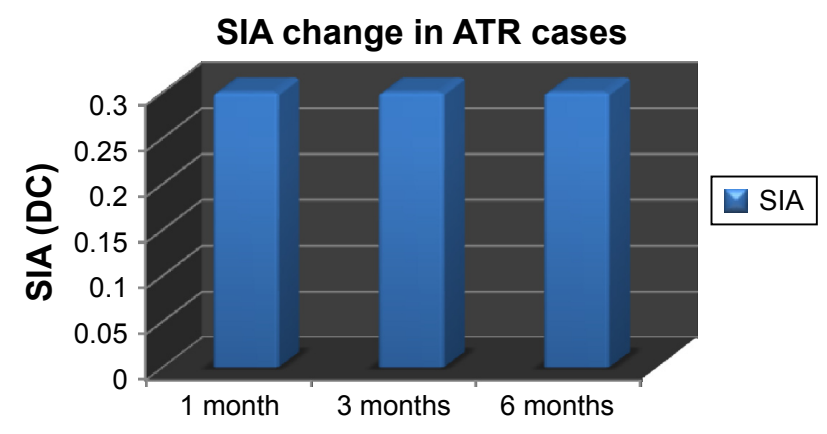

Figure 8 SIA changes in ATR astigmatism cases.

Abbreviations: SIA, surgically induced astigmatism; ATR, against the rule.

to $0.50 \mathrm{DC}$ at 6 months, our study achieved much better SIA at 1 month in comparison.

Our results are much better than a recent study done by Simsek et al, ${ }^{11}$ using superior incision. This study achieved 1.44 DC SIA at 3 months. The argument of this study is that the higher SIA was due to pressure of the upper lid on the superior cornea and not the incision itself, especially that the astigmatism was ATR.

The temporal incision in our study resulted in less SIA than other studies that employed a TCCI as well. Yoon et $\mathrm{al}^{7}$ achieved a mean $0.81 \mathrm{DC}$ at 1 month, which later on decreased to $0.53 \mathrm{DC}$ at 3 months. We had also better SIA than the study of Pakravan et al, ${ }^{6}$ who achieved a mean $0.63 \mathrm{DC}$ at 1 month, which gradually decreased to $0.26 \mathrm{DC}$ at 6 months. Barequet et $\mathrm{al}^{9}$ achieved a mean $0.74 \mathrm{DC}$ at 6 weeks. Kohnen et $\mathrm{al}^{8}$ had a SIA of $0.62 \mathrm{DC}$ at 2 weeks, which decreased to $0.47 \mathrm{DC}$ at 6 months. We had a stable SIA over the 6 months follow-up. This is different from the gradual reduction of SIA in these studies. This may be due to the smaller incision size used in our study $(2.4 \mathrm{~mm})$.

Working with both hands helped our study to be done using TCCIs in all cases whether right or left eye. We had much better SIA than that elicited by performing nasal clear

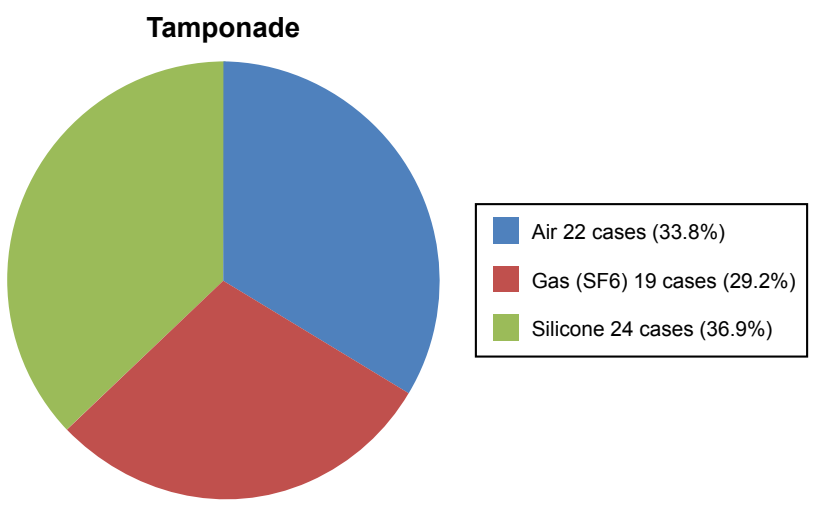

Figure 9 Tamponading agents in the study.
Table 3 KA change with different tamponades

\begin{tabular}{lll}
\hline Tamponade & Preoperative KA (DC) & Postoperative KA (DC) \\
\hline Air & 0.93 & 0.73 \\
Gas & 0.95 & 0.63 \\
Silicone oil & 1.30 & 1.06 \\
\hline
\end{tabular}

Abbreviation: KA, keratometric astigmatism.

corneal incisions in other studies. This was done for left eyes. The major disadvantage of nasal incision is intraoperative difficulty from nasal bridge. In addition, it results in much more SIA. Pakravan et $\mathrm{al}^{6}$ achieved a mean $1.80 \mathrm{DC}$ at 1 month, which decreased to $0.92 \mathrm{DC}$ at 6 months. Yoon et al ${ }^{7}$ had a mean $0.92 \mathrm{DC}$ at 1 month, which decreased to 0.62 at 6 months. Barequet et $\mathrm{al}^{9}$ achieved a mean $1.65 \mathrm{DC}$ SIA at 6 weeks, which persisted at 12 months (1.41 DC). Kohnen et $\mathrm{al}^{8}$ had a mean $1.55 \mathrm{DC}$ at 2 weeks, which decreased to $1.05 \mathrm{DC}$ at 6 months.

We had a similar SIA to other studies where a TCCI of 2.2-2.4 mm size was done. Luo et $\mathrm{al}^{12}$ achieved a mean $0.28 \mathrm{DC}$ at 1 month in the $2.2 \mathrm{~mm}$ group, and $0.86 \mathrm{DC}$ at the $3.0 \mathrm{~mm}$ group.

Unintentionally, most of the recruited cases had preoperative ATR astigmatism. This explains why in spite of dead temporal incision, there was a minimal SIA $(0.30 \mathrm{D})$ in the cases. We had only four eyes with WTR astigmatism, and they showed an initial worsening at 3 months $(0.53 \pm 0.12 \mathrm{D})$, then gradual improvement, but still to a higher level at 6 months $(0.48 \pm 0.16 \mathrm{D}){ }^{6}$

Three types of tamponading agents were used in the study: air, SF6 gas, and silicone oil. The type of tamponade did not influence the SIA in the patients all over the study duration. Even though silicone oil cases had the highest postoperative KA, they had the highest preoperative KA,

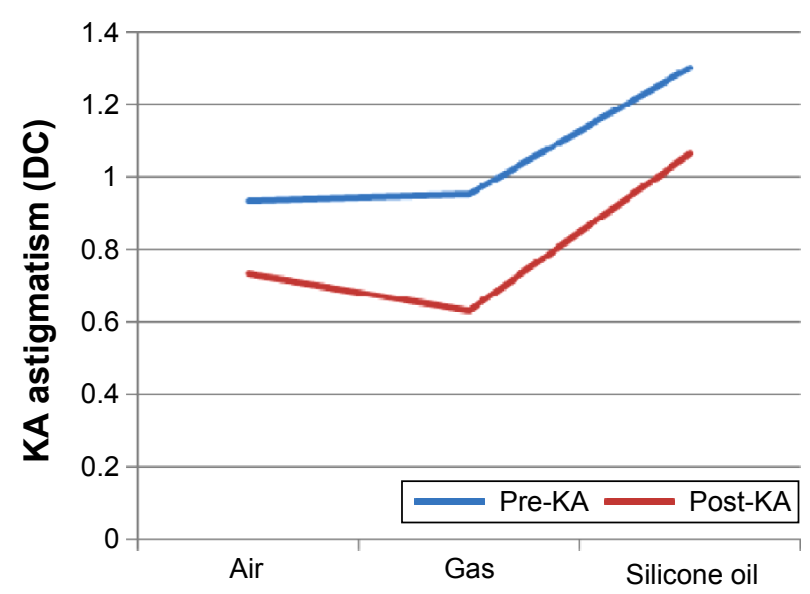

Figure $10 \mathrm{KA}$ change with different tamponades. Abbreviations: KA, keratometric astigmatism; DC, diopters cylinder. 
and the same SIA values. It is compatible with literature data about refractive changes with silicone oil fill, which are either hyperopic or myopic, depending on the lens status. $^{13-15}$

Our study had a better SIA because all the horizontal clear corneal incisions were temporal, and also the incision size was $2.4 \mathrm{~mm}$; however, the major limitation of our study is the short follow-up of SIA for only 6 months, compared to long durations up to 12 months in some studies. ${ }^{10,12,16,17}$

\section{Conclusion}

Superior sitting TCCI phacoemulsification during combined phacovitrectomy proved safe and easy, without the burden of changing the operative setting, with an acceptable anatomical and optical outcome.

\section{Author contributions}

All authors contributed toward data analysis, drafting and revising the paper and agree to be accountable for all aspects of the work.

\section{Disclosure}

The authors report no conflicts of interest in this work.

\section{References}

1. Lee DY, Jeong HS, Sohn HJ, Nam DH. Combined 23-gauge sutureless vitrectomy and clear corneal phacoemulsification in patients with proliferative diabetic retinopathy. Retina. 2011;31:1753-1758.

2. Soheilian M, Mirdehghan SA, Peyman GA. Sutureless combined 25 gauge vitrectomy, phacoemulsification and posterior chamber intraocular lens implantation for management of uveitic cataract associated with posterior segment disease. Retina. 2008;28:941-946.

3. Sisk RA, Murray TG. Combined phacoemulsification and sutureless 23 gauge pars plana vitrectomy for complex vitreoretinal diseases. Br J Ophthalmol. 2010;94:1028-1032.

Clinical Ophthalmology

\section{Publish your work in this journal}

Clinical Ophthalmology is an international, peer-reviewed journal covering all subspecialties within ophthalmology. Key topics include: Optometry; Visual science; Pharmacology and drug therapy in eye diseases; Basic Sciences; Primary and Secondary eye care; Patient Safety and Quality of Care Improvements. This journal is indexed on
4. Heath $\mathrm{G}$, Rahman R. Combined 23 gauge sutureless transconjunctival vitrectomy with phacoemulsification without facedown posturing for the repair of idiopathic macular holes. Eye(Lond). 2010;24:214-220.

5. Sood V, Rahman R, Denniston AK. Phacoemulsification and foldable intraocular lens implantation combined with 23 gauge transconjunctival sutureless vitrectomy. J Cat Refract Surg. 2009;35:1380-1384.

6. Pakravan M, Nikkhah H, Yazdani S, Shahabi C, Rahimabadi MS. Astigmatic outcomes of temporal versus nasal clear corneal phacoemulsification. J Ophthalmic Vis Res. 2009;4(2):79-83.

7. Yoon JH, Kim KH, Lee JY, Nam DH. Surgically induced astigmatism after $3.0 \mathrm{~mm}$ temporal and nasal clear corneal incisions in bilateral cataract surgery. Indian J Ophthalmol. 2014;61(11):645-648.

8. Kohnen S, Neuber R, Kohnen T. Effect of temporal and nasal unsutured limbal tunnel incisions on induced astigmatism after phacoemulsification. J Cat Refract Surg. 2002;28(5):821-825.

9. Barequet IS, Yu E, Vitale S, Cassard S, Azar DT, Stark WJ. Astigmatism outcomes of horizontal temporal versus nasal clear corneal incision cataract surgery. J Cat Refract Surg. 2004;30(2):418-423.

10. Holladay JT, Cravy TV, Koch DD. Calculating the surgically induced refractive change following ocular surgery. J Cat Refract Surg. 1992; 18(5):429-443.

11. Simsek S, Yasar T, Demirok A, Cinal A, Yilmaz OF. Effect of superior and temporal clear corneal incisions on astigmatism after sutureless phacoemulsification. J Cat Refract Surg. 1998;24(4):515-518.

12. Luo L, Lin H, He M, Congdon N, Yang Y, Liu Y. clinical evaluation of three incision size-dependent phacoemulsification systems. Am J Ophthalmol. 2012;153(5):831-839.

13. Hotta K, Sugitani A. Refractive changes in silicone oil filled pseudophakic eyes. Retina. 2005;25(2):167-170.

14. Smith RC, Smith GT, Wong D. Refractive changes in silicone oil filled eyes. Eye(Lond). 1990;4(Pt 1):230-234.

15. Hoffman A, Wolfer J, Occelli L, et al. Refractive state following retinal reattachment and silicone oil tamponade in dogs. Am J Vet Res. 2012; 73(8):1299-1304.

16. Kohnen T, Dick B, Jacobi KW. Comparison of the induced astigmatism after temporal clear corneal tunnel incisions of different sizes. J Cat Refract Surg. 1995;21(4):417-424.

17. Anders N, Pham DT, Antoni HJ, Wollensak J. postoperative astigmatism and relative strength of tunnel incisions: a prospective clinical trial. J Cat Refract Surg. 1997;23:332-336.

\section{Dovepress}

PubMed Central and CAS, and is the official journal of The Society of Clinical Ophthalmology (SCO). The manuscript management system is completely online and includes a very quick and fair peer-review system, which is all easy to use. Visit http://www.dovepress.com/ testimonials.php to read real quotes from published authors. 